\title{
"LOBO MAU": ANALISADOR DA TRANSVERSALIDADE ENTRE ORGANIZAÇÃO DO TRABALHO \& SAÚDE MENTAL?
}

\author{
Fabiana Nunes Merhy-Silva ${ }^{\star}$
}

\begin{abstract}
Resumo
Este trabalho tem por objetivo elucidar a construção do analisador "Lobo-Mau" - expressão utilizada por alguns autores para indicar a atuação da Psicologia-nasorganizações quando atua contra a saúde-mental-dos-trabalhadores, em favor da produtividade-organizacional. Partindo de nossas implicações com as instituições Saúde-do-Trabalhador, Análise-Institucional e Psicodinâmica-do-Trabalho, tomamos a idéia de "Lobo-Mau" como um analisador da transversalidade entre Organização-do-Trabalho e Saúde-Mental. Tal analisador permitiu-nos colocar em dia nossas implicações-institucionais com a Análise-Institucional e a Psicodinâmica-do-Trabalho; colocando-se como contra-ponto às abordagens hegemônicas em Saúde-do-Trabalhador e suas formulações-prescritas que têm servido à uma maior exploração da saúde mental do(s) trabalhador(es).
\end{abstract}

Palavras-chave: "Lobo Mau”. Analisador. Transversalidade. Saúde Mental e Trabalho. Saúde do Trabalhador.

\section{"LOBO MAU" ("BAD WOLF"): ANALYST OF TRANSVERSE BETWEEN WORK ORGANIZATION \& MENTAL HEALTH?}

\begin{abstract}
This work has to objective elucidate the construction of analyst- "Lobo Mau" in psychology. Starting from ours implications with the institutions worker'shealth, institutional-analysis and psychodynamic-of-work, we can obtain the idea of "Lobo-Mau" - utilized for some authors to describe the psychology in the organizations - with an analyst-of-transverse between work-organization and mental-health. The construction and elucidation of analyst-"Lobo-Mau", ours allowed put up date ours institutional-implication with the institutional-analysis and the psychodynamic-of-work. A such analyst put in for (submit) on the other hand a dominant approach in worker's-health and yours formulations that has been used to one a bigger exploration of worker's-mental-health.

Keywords: "Lobo mau". Analyst. Transverse. Mental health and work. Worker's health.

\footnotetext{
^ Psicóloga Clínica do Trabalho. Analista Institucional. Professora. Pesquisadora. Mestre em Saúde Coletiva- IESC-UFRJ. Doutoranda ESS-UFRJ. Membro do Projeto Transversões - ESS-UFRJ. Endereço: Rua Trinta e Um de Maio, n 47. Bairro: Ladeira. Juiz de Fora, MG. CEP 36052-580.

E-mail: fanume@iesc.ufrj.bre merhy_silva2005@yahoo.com.br
} 


\section{INTRODUÇÃo}

Desde já buscamos esclarecer que estamos tomando a Saúde Mental como "instituição"1 - por estar referida ao "instituinte originário"2 (CASTORIADIS, 1973), bem como todos àqueles que a encarnam, noutros termos, os Trabalhadores em Saúde Mental (TSM) os quais se situam na encruzilhada da loucura (MARAZINA, 1989). Para nós, saúde - enquanto vir-a-ser -, está atrelada à emancipação dos usuários dos serviços de Saúde Mental e dos TSM, sendo a resultante de um processo de produção³ (SARTRE, 1963; MINAYO, 1991; CAMPOS, 2000).

Este "novo conceito de saúde" (DEJOURS, 1986) enfoca o papel do trabalho na saúde dos indivíduos colocando em pauta o que, no processo de trabalho, atinge a saúde mental dos coletivos e atribui a responsabilidade pelo "sofrimento mental do trabalhador" à "organização do trabalho" - entendida como:

[...] não só a divisão do trabalho (divisão das tarefas entre os operadores, os ritmos impostos e os modos operatórios prescritos) mas também e sobretudo, a divisão dos homens para garantir esta divisão de tarefas, representada pelas hierarquias, as repartições de responsabilidade e os sistemas de controle (DEJOURS, 1992a, p. 10).

Atualmente, mais do que nunca, a(s) questão(ões) ligadas à Saúde Mental e/no Trabalho e suas intrincadas tramas com a "organização do trabalho" necessitam estar sob interrogação. Conseqüentemente, pesquisas sobre saúde mental e trabalho não podem se dar ao luxo de se instalarem como mero ramo aplicado do campo Psi (Psicologia, Psiquiatria, Psicanálise), nem serem privativas de qualquer outro campo que venha a requerer direitos exclusivos sobre o processo saúde-doença mental. Sendo assim, faz-se urgente pôr em questão a não naturalidade do "processo saúde-doença mental", estando este diretamente atravessado pelo processo de produção.

Em função da pluralidade inerente à temática Saúde Mental e Trabalho (JACQUES; CODO, 2002; CODO et al., 2004), não a tomaremos enquanto campo específico, e sim como vários que aí se entrecruzam, apropriando-se de saberes e discursos (FOUCAULT, 1996; VASCONCELOS, 1997, 1999, 2000, 2001; VENÂNCIO; CAVALCANTI, 2001).

A produção do discurso do "Lobo Mau" aparece em algumas publicações que colocam em debate o(s) papel(éis) do Psicólogo na Organização Industrial, levantando algumas notas sobre o "Lobo Mau" em Psicologia 4 .

A idéia de "Lobo Mau" - utilizada por alguns autores para descrever a Psicologia nas organizações (CODO, 1994; RODRIGUES, 1997) -, condiz com a atuação de alguns representantes da Psicologia Industrial e da Psicologia Organizacional que têm trabalhado contra a saúde (mental) dos trabalhadores, e em favor da produtividade organizacional em que o binômio saúde-doença se 
encontra inextricavelmente condicionado por práticas capitalísticas de controle (psicopatologizante) dos corpos, pela via da "dupla-penalização"s (MINAYOGOMES; THEDIM-COSTA, 1997) aos trabalhadores/as.

Esta questão ("Lobo Mau") é falsa na medida em que enquanto se ficava na dicotomia de que há uma "boa leitura" e uma "má leitura" na Psicologia (existe os que são a favor das políticas pró-mercado e os que são contra ela), isso mascarava que o neoliberalismo está avançando de maneira a tratar todo e qualquer problema social como fatos de redução psicologizante.

Numa tentativa de questionar o "Lobo Mau" no trabalho e sua prescrição à uma determinada Psicologia, o presente trabalho tem por objetivo elucidar a construção do analisador "Lobo Mau" em Psicologia.

A fundamentação teórica e os procedimentos metodológicos foram construídos a partir da Análise Institucional e da Psicodinâmica do Trabalho.

Nos trabalhos socioanalíticos são privilegiados fatos, falas e acontecimentos que possam produzir rupturas nos modos "naturalizados" de lidar com o cotidiano - ou seja, os analisadores - "acontecimentos; ou fenômenos reveladores $e$ ao mesmo tempo catalisadores; produtos de uma situação que agem sobre ela" (LOURAU, 1977-2004b, p. 69; LAPASSADE, 1973, 1979; RODRIGUES; SOUZA, 1991; RODRIGUES, 1992, 1999a, 2004; BARROS; BRASIL, 1992; BAREMBLITT, 1998).

Os analisadores permitem a análise pois revelam "a especificidade da instituição na qual se encontra" (HESS; AUTHIER, 1981-1994, p. 79) e o "trabalho dos analisadores é que precede e funda o trabalho de análise" (LAPASSADE, 1973, p. 39).

Enquanto dispositivo artificial/“natural" ou construído, o analisador ${ }^{6}$ aquilo que produz análise -, por ser a via de mediação, facilita a apropriação e popularização da análise (ARDOINO; LOURAU, 2003, p.24).

Em busca de desnaturalizar a produção do "Lobo Mau" em Psicologia, partimos da análise de nossas "implicações" com as "instituições" Saúde Mental, Saúde Mental e Trabalho, Saúde do Trabalhador, Análise Institucional e Psicodinâmica do Trabalho, e daí tomamos a metáfora do „Lobo Mau\%๕omo um ,analisador\%da ,transversalidade\%œentre Organização do Trabalho e Saúde Mental.

\section{QUe IMPLICAÇões?}

Não é a implicação [...] o objeto de análise das relações que temos com a instituição e, antes de tudo, com nossa instituição de pertencimento mais próxima, aquela que possibilita nossa inserção nas situações sociais de intervenção, de formação e de pesquisa?

René Lourau 
O que caracteriza este "novo espírito científico" institucionalizado por Guattari (1973) e incorporado por Lourau é colocar a "implicação" como "o objeto de análise das relações que temos com as instituições". Ao levantar a questão - até que ponto as implicações com nossa instituição de pertencimento mais próxima possibilitaria "nossa inserção nas situações sociais de intervenção, de formação e de pesquisa?" (LOURAU, 1996-2004c, p. 239) -, o autor abre caminho para buscarmos qual(ais) o(s) lugar(es) da(s) implicação(ões) na produção de conhecimento. Através do conceito de implicação, em algumas formulações socioanalíticas diz-se que são "as instituições" (em sentido conceitual) "que nos atravessam", sendo nossas percepções, afetos e pensamentos marcados pelas relações com a Família, a Escola, a Psiquiatria, o Trabalho, o Estado, entre outros. Melhor dizer: estamos "implicados com" ou "atravessados por elas".

Um eixo importante, tributário dos trabalhos de Lourau (1969-2004a) sobre a "análise da(s) implicação(ões)" é a distinção dos níveis em que se manifesta a implicação do "pesquisador": em seu objeto de pesquisa/intervenção; na instituição de pesquisa, a começar pela equipe de pesquisa/intervenção; na encomenda e nas demandas sociais; na epistemologia de seu campo disciplinar; enfim, na escritura ou qualquer outro meio utilizado para a exposição da pesquisa. Cada um dos níveis citados amplia o exame das "dimensões" organizacionais e materiais, libidinal e afetiva, ideológica e política da implicação (HESS; SAVOYE, 2006, no prelo).

Frise-se que a crítica ao instituído ${ }^{9}$, no que diz respeito às formas políticas de ação em Psicologia do Trabalho, inquietava-nos desde o início de nossa prática - inaugurada em 1994, num estágio em uma Associação Municipal de Apoio Comunitário (AMAC), a qual coordenava 18 creches -, em função de se atribuir o lugar de "Lobo-Mau" à Psicologia das Organizações (CODO, 1994; RODRIGUES, 1997; MERHY-SILVA, 2006). Tal crítica é uma autocrítica que porta, em germe, a noção de implicação do observador naquilo que observa. Já não nos era possível, então, seguir as prescrições associadas à Psicologia Industrial e Organizacional ${ }^{10}$ (Seleção e Orientação). As instâncias dirigentes, à época, decidiram que teríamos de "dobrar" nosso turno de estágio, passando a atuar especificamente com "testagem". Foi aí que rompemos com esse estágio - não só literalmente, mas indo em busca de outra Psicologia do Trabalho, a qual não estava dada de antemão. O fato de termos iniciado o curso de Psicologia em meados de 1993 não favorecia, até aquele momento, a oferta de um aparato teórico "consistente"; mas as inquietações que fervilhavam a partir das experiências - nossas atividades de estagiária incluíam observar diretamente a coordenação geral dos serviços de Psicologia das creches, propiciando um mergulho em questões tecidas na trama "estabelecimentos-grupos-organizações-instituições" - muito contribuíram para nossos investimentos futuros em "formação paralela".

A prestação de serviços institucionais a um estabelecimento imobiliário, que constituiu o campo de intervenção primordial analisado na dissertação (MERHY-SILVA, 2006), inaugura um novo período em nossas buscas por uma 
(ou várias?) Psicologia(s) do Trabalho humano, passível(eis) de contribuir para a conquista de espaços em que produção de conhecimento, intervenção e formação pudessem ocorrer.

Nossas atividades de docente (no período de 2001) da disciplina "Psicologia Organizacional" para as turmas da Faculdade de Ciências Gerenciais do curso de Administração voltado para o Comércio Exterior (ocorridas no interior de Minas Gerais) contribuíram para a exacerbação das inquietações quanto aos moldes em que o trabalho humano se tem desenhado, chegando ao cúmulo de nos ser praticamente proibido pela direção informar aos alunos sobre questionamentos referentes à saúde (inclusive mental) dos trabalhadores. Este caldo de cultura parece refletir os ecos do duelo entre a Organização Internacional do Trabalho (OIT) e a Organização Mundial do Comércio (OMC), colocando em "banho-maria" a histórica conquista dos direitos dos trabalhadores. Daí que no subtexto dos códigos de conduta há uma hostilidade pela idéia de que os cidadãos possam assumir o controle de suas próprias condições de trabalho e do impacto ecológico da industrialização. Antes, porém, que os alunos sejam informados e venham a (re)apropriar-se de seus saberes e poderes, prescrições organizacionais - como a anteriormente citada - são emitidas, com o intuito de evitar que os trabalhadores (a maioria dos alunos o são) reivindiquem seus direitos (o equivalente, ali, a se rebelarem).

Em meados de 2002, tivemos acesso ao Instituto de Psiquiatria (IPUB) da UFRJ, onde participamos do estágio probatório na linha de pesquisa do programa "Organização do Trabalho e Saúde Mental" (OTSAM) ${ }^{11}$ O presente texto é fruto da experiência no contexto do OTSAM.

Uma maior contextualização de nossas implicações com a instituição da Saúde Mental, a Análise Institucional e a Psicodinâmica do Trabalho pode ser apreendida em nossa dissertação "Análise Institucional, Psicodinâmica do Trabalho \& Saúde Coletiva: tecendo interconexões com a assistência à saúde mental de trabalhadores corretores de imóveis (1996-2006)"'12 (MERHY-SILVA, 2006) desenvolvida no Mestrado em Saúde Coletiva no Instituto de Estudos em Saúde Coletiva -IESC da Universidade Federal do Rio de Janeiro -UFRJ.

O trabalho tece conexões entre a Análise Institucional (AI), a Psicodinâmica do Trabalho (PDT) e a Saúde Coletiva (SC), mediante a análise dos serviços prestados à assistência à Saúde Mental de trabalhadores Corretores de Imóveis de um estabelecimento imobiliário familiar, no interior de Minas Gerais. Além de tecer tais conexões, buscamos compreender a produção de "sofrimento psíquico" relacionado ao trabalho, mediante a análise de intervenções institucionais realizadas com os Corretores de Imóveis.

No período 1996-2003, a partir de um pedido de "trabalho psicológico" com Corretores de um estabelecimento ${ }^{13}$ imobiliário, instauraram-se procedimentos fundados em ferramentas da Análise Institucional e da Saúde Coletiva. As práticas desenvolvidas apoiaram-se em diretrizes socioanalíticas: análise coletiva da encomenda e das demandas, autogestão, construção/intensificação de analisadores e análise de implicações. 
A partir da descrição das intervenções com os Corretores de Imóveis, articulamos os campos da Análise Institucional, Psicodinâmica do Trabalho e Saúde Coletiva. A necessidade de construir ganchos entre tais campos brotou do "campo de intervençãon" assinalado. Embora nos arquivos acadêmicos a "esquizofrenização" disciplinar opere para que cada coisa fique no seu devido lugar (como se uma coisa não tivesse nada a ver com a outra), na prática, a organização real do trabalho apontou que alguns conceitos, ainda que se apresentem totalmente díspares, foram sendo ligados no bojo dessas intervenções, propiciando, em alguns momentos, a descoberta de permeabilidades muito interessantes entre conceitos aparentemente desconexos. Assim, a revisão do trabalho realizado com os Corretores (desde 1996) possibilitou ampliar nosso "campo de análise" através de outros elementos conceituais.

Com base na descrição da assistência prestada e nas ligações que se estabelecem, no interior dessas trajetórias, foram identificados os "ruídos"14, que funcionaram como elementos interrogadores das destoantes 'lógicas' do processo de trabalho, tanto dos Corretores, quanto dos socioanalistas, bem como das relações que estes entrelaçam. Psico-Lógicas envolvidas na produção do cuidado em si?

De acordo com Merhy (MERHY; ONOCKO, 1997), são considerados ruídos os "estranhamentos" ou as contradições do processo de trabalho que poderão ser identificados ao longo da análise das trajetórias-sentinela ou outros dispositivos analisadores, utilizados para a análise molecular da produção do cuidado (em saúde).

Quanto a formas escritas ou faladas do discurso organizacional que podem, - enquanto analisador ${ }^{16}$-, revelar o não-dito institucional, adiante buscamos esclarecer: o que acontece quando alguém diz algo, em determinado contexto, momento e lugar e isso pode abrir diálogos com outros atores e questões? E sendo justamente este abrir falas, produzir análise, o papel de um analisador, vamos nos aproximando do analisador "Lobo Mau" em Psicologia.

\section{"LOBO MAU": UM ANALISADOR?}

Discutir o "Lobo Mau" em Psicologia como um analisador que emergiu meio à dinâmica dos serviços prestados à assistência à Saúde Mental de trabalhadores Corretores de Imóveis, possibilitar-nos-á a elucidação do analisador "Lobo Mau" ${ }^{17}$.

A expressão Lobo Mau foi utilizada por alguns autores para indicar a atuação da Psicologia nas organizações quando atua contra a saúde mental dos trabalhadores/as, em favor da produtividade organizacional. Tal crítica é lançada por Codo (1994) no contexto da publicação de "Psicologia Social: o Homem em Movimento"18 (CODO; LANE, 1994), esquentando o debate a respeito de qual(is) o(s) papel(éis) do Psicólogo na Organização Industrial (e dos Serviços) (RODRIGUES; SOUZA, 1991; RODRIGUES, 1997; ATHAYDE, 1992, 2004; AZEVEDO, 1993; entre outros).

E como é que então o "Lobo Mau" se impõe como questão? 
Foi através dos seminários do OTSAM-IPUB-UFRJ (2002) que Sílvia Rodrigues Jardim apresentou a produção de "A Danação do Trabalho: Organização do Trabalho e Sofrimento Psíquico" (JARDIM; SILVA-FILHO, 1997) onde Rodrigues (1997), ao ser convidada pelos organizadores do evento-publicação a expor acerca do tema "compreensão e crítica da Psicologia do Trabalho", retoma a expressão "Lobo Mau":

O Psicólogo do Trabalho já foi apelidado o "lobo mau" da Psicologia.Não é seu destino, pois destino não há! Mas decerto não é através de declarações de princípio que "o trabalhador em saúde mental do trabalhador" se transformará em "carneirinho". Apenas estamos começando a engendrar, talvez, um novo agente, e este quer sair desta fábula, pois se vê estrategista/aventureiro da vida. E já que falamos de animais - abelhas, lobos e carneiros - vale finalizar parafraseando Deleuze, como parte de nossa conspiração/conluio: "Por que não ser psicólogo do trabalho (ou pesquisador em saúde do trabalhador) me impediria de falar de tal coisa, se falo dela como um cão? (RODRIGUES, 1997, p. 342).

No entanto, assim como Codo (1994), Rodrigues (1997) aí não esclarece de onde vem a expressão "Lobo Mau". Instigada por este "não-dito" a respeito da gênese contextual do Lobo Mau em Psicologia, levantei diversas questões, sem pretensão de respondê-las: Como se constroem os discursos e quais são as condições de sua produção? (FOUCAULT, 1980; BASTOS, 2004). Qual(is) o(s) lugar(es) do Lobo Mau entre a História da Psicologia ligada ao trabalho e dos "modelos" de organização do trabalho? Que inversão de lugares no discurso na tentativa de manipular a prática de ocupação do the right man in the right place tem sido proposta (e muitas vezes aceita pelos representantes da psicologia) na atribuição da psicologia na organização industrial ao Lobo Mau? De que Lobo Mau se trata? Ou, de fato, o que vem a significar esta distribuição de posto de trabalho enquanto Lobo Mau à psicologia? Que deslocamentos de Lobo Mau esta consideração em voga carrega nesse discurso implicitamente? Quem tem medo do Lobo Mau?

A questão aqui, como já foi dito, é que a categoria "Lobo Mau" não só é simplória, como também mascara que, em determinado contexto, com a emergência do neoliberalismo, os problemas humanos passam a ser tratados pela ordem exclusiva do sujeito, ou seja, há a partir daí uma "psicologização" da sociedade. Em outras palavras, sob a égide da transversalidade social pró-mercado, tudo é psicologizado.

Numa tentativa de buscar de onde vem esse discurso do "Lobo Mau" no trabalho e sua prescrição à uma determinada psicologia, procuramos reunir algumas notas sobre a temática uma vez que a Saúde do Trabalhador ${ }^{19}$ enquanto campo é permeada por formações discursivas da "Academia, dos Serviços e do Movimento Sindical" (LACAZ, 1996). 
Quanto ao "modo de produção dos analisadores"20 (LOURAU, 2004c, p. 244), ao colocarmos o discurso do "Lobo Mau" sob interrogação, visamos explicitar como detectamos o instituído - "Lobo Mau" - em nossa prática.

Com base na análise de nossas práticas nas "instituições concretas", problematizar a produção dos discursos - especificamente o de "Lobo Mau" -, pode contribuir para que façamos uma leitura da Ordem dos poderes que se encontram no fluxo dos discursos que são produzidos/reproduzidos e ocorrem transversalmente nas instituições (BASTOS, 2004).

A análise de instituições concretas, tal como a propõe José Augusto Guilhon de Albuquerque consiste em apreender a instituição como uma "estrutura de práticas, ou de relações sociais institucionalizadas que tendem a se reproduzir e a se legitimar" (ALBUQUERQUE, 1978, 1982; GUIRADO, 1987), sendo que a legitimidade dessas práticas supõe as imagens que se constituem a respeito do lugar ou do papel que os atores institucionais (ALBUQUERQUE, 1978) nelas ocupam, possibilitando pensar as representações como "o nível subjetivo - entendido como o nível da identificação imaginária que é ocasião de algum reconhecimento e de desconhecimento na/da ordem das relações instituídas - da organização e da estruturação da prática" (GUIRADO, 2004, p. 44). Ao propor a análise de uma instituição concreta, Albuquerque diferencia o plano das relações materiais (políticas e econômicas) do plano das relações ideológicas. Em suma, no entender de Albuquerque (1978), as instituições são concretas na medida em que podem ser discutidas através de seu acontecer diário - pela via dos discursos, das práticas de seus agentes e de sua clientela (BASTOS, 2004). Sendo exatamente tais relações entre os agentes e a clientela que definem o objeto institucional - isto é, "das relações sociais que se instituem na apropriação de algum objeto imaterial e impalpável, em nome do qual aquelas práticas existem" (GUIRADO, 2004, p. 47). Ou, "o objeto institucional é aquilo sobre cuja propriedade a instituição reivindica o monopólio de legitimidade. Definir-se como instituição é apropriarse de um objeto" (ALBUQUERQUE, 1978, p. 70), apropriação de um território feita por determinados saberes/poderes.

Se dentre o papel/lugar atribuído ao Psicólogo na correlação Organização do Trabalho e Saúde Mental, podemos "encontrar" o "Lobo Mau", há também a função relacionada a um papel profissional de "fazer pensar a instituição como um conjunto de práticas sociais que se reproduzem e se legitimam" (GUIRADO, 2004). Contudo, tal repensar se realiza a partir da análise dos discursos nas relações instituídas, através dos "cortes que fazem pensar" (GUIRADO, 1987).

Passeemos pela estrada afora...

Não desavisados de que "a estrada é longa, o caminho é deserto e o Lobo Mau passeia aqui por perto", eis que nos deparamos com o lobo, encontro inevitável numa bifurcação da estrada. Mas o que vem a significar esse ponto de bifurcação da estrada? 
Na estrada da Saúde do(s) Trabalhador(es/as), tal bifurcação corresponde à encruzilhada do processo de produção de saúde, - tensão entre as lógicas instituídas versus práticas de desinstitucionalização (instituintes) -, onde podemos buscar possibilidades de quebra da lógica predominante na saúde e sua desconstrução atravessa o "espaço da micropolítica, o espaço da organização do trabalho e das práticas" (GUATTARI; ROLNIK, 2005; MERHY; ONOCKO, 2002).

Como tornar visível o "institucional" - como lógica social invisível -, para poder compreender os sentidos do movimento contraditório entre forças instituídas e instituintes, as causas e conseqüências dos encadeamentos inconscientes das situações que nos institucionalizam? "Atuar com o intento de transformar essa lógica" implica construir os "analisadores" (MARTIN, 2004).

A "situação de trabalho"21 na qual o analisador "Lobo Mau" se impôs é originária da assistência à Saúde Mental de Trabalhadores Corretores de Imóveis. Foi em 1999, em um dos momentos do processo de devolução aos trabalhadores/ as que o gestor-corretor ${ }^{22}$ tentou impedir que "o trabalho continuasse", "boicotando" o acesso da validação coletiva (do material levantado a partir das intervenções com os Corretores) aos trabalhadores/as. Frente a tal impasse de poder (ou não) continuar a realizar o trabalho socioanalítico, a pesquisadora em campo (no caso, eu mesma) prescreveu: "Vá para a Clínica! [Psi] Para que a Análise Institucional e a Psicodinâmica do Trabalho continuem a existir". ${ }^{23}$

Num a posteriori, ao discutir com o staff de socioanalistas a referida prescrição, ${ }^{24}$ tal procedimento pode ser visto como uma espécie de "efeito analisador" do que se desconhece ou se reconhece das relações institucionais concretas. Destarte, identificou-se aí o analisador "Lobo Mau".

A construção do analisador - enquanto manifestações de não-conformidade com o instituído são, elas mesmas, reveladoras da natureza do instituído (LOURAU, 2004b, p. 69). Quando afirmamos conhecer a crítica "Lobo Mau" atribuída aos profissionais Psis envolvidos na organização industrial e dos serviços, não podíamos imaginar que cairíamos nas armadilhas do instituído ("Lobo Mau"). No entanto, é justamente através desta captura, que o analisador "Lobo Mau" se revela.

Revisitar os analisadores, possibilita colocar em evidência o quanto "os interventores estão totalmente implicados na elaboração dos analisadores da situação" (LOURAU, 2004c, p. 243, grifo nosso). É neste sentido que Hess (1975) considera a teoria dos analisadores como um dos aspectos cruciais da socioanálise já que "o analisador é o elemento que permite atualizar, colocar em dia as implicações institucionais" (HESS, 1975, p. 55, grifo nosso).

O dispositivo de análise das implicações é uma tentativa de "vacina" - para que não se assuma o lugar do instituído e, neste caso, do Lobo Mau - mas não pode garantir a transparência para quem está fazendo esta análise e os embates de poder (FOUCAULT, 1979, 1988) "obrigam" a assumir posições que têm sustentação no mandato profissional e na legitimidade que até então a profissão alcançou com todos os seus compromissos conservadores (o instituído). 
Como se os fins justificassem os meios, a justificativa - " [...] Para que a Análise Institucional e a Psicodinâmica do Trabalho continuem a existir" - foi pronunciada com a aparente finalidade de encaminhar - "Vá para a Clínica ..." [Psi] - como um enquadre de trabalho que remonta ao já instituído no âmbito Psi quanto a indicar tratamento individual quando detectar questões que não poderiam ser trabalhadas no nível coletivo (já que a proposta não é terapia de grupo nem Psicoterapia Institucional (OURY, 1976; AYME, 1995; ALTOE, 2004). No entanto, além de denunciar o modo como o espaço técnico é espaço de luta de poder, o analisador "Lobo Mau" permite desatar o que está em jogo nessa situação: a própria "institucionalização" da Análise Institucional no Brasil. Neste caso, a institucionalização da pesquisa-intervenção (MERHY-SILVA, 2006) na Saúde Coletiva puxa o fio que desenrola concomitantemente o tornar-se Corretor/a de Imóveis e o tornar-se Analista Institucional.

\section{Considerações Finais (ou Iniciais?)}

Quanto às revelações do analisador "Lobo Mau", indicam que:

$1^{\circ} \mathrm{O}$ "pano de fundo" no qual a costura neoliberal se tece é paralelo à formação de uma "psicologização" da sociedade. Enquanto isso, a Psicologia ligada à Organização Industrial é taxada de "Lobo Mau". Ou seja, a conotação dicotômica (do bem e do mau) parecia esconder uma costura transversal a partir da clínica, tentando psicologizar os problemas sociais pela reprodução da transversalidade social, ligada ao padrão neoliberal.

$2^{\circ}$ Esta reprodução da transversalidade tem a ver com dois fatores:

entender o que é a transversalidade hoje: como rede de reprodução da ordem hegemônica e um outro sentido que é o de oposição/ruptura em relação à hegemonia.

Esta transversalidade é sinônimo da produção de subjetividade no mundo globalizado (GUATTARI; ROLNIK, 1977, 2005).

$3^{\circ}$ Vai desvelar a "instituição concreta" no sentido da subjetividade hegemônica. Isto é, os problemas/programas sociais, em tese, são reduzidos à psicologização da sociedade. Como contraponto, o "Lobo Mau" pode ser tomado como analisador da transversalidade entre Organização do Trabalho e Saúde Mental. Discutir a categoria "Lobo Mau" como um analisador é desvelar os serviços de Saúde Mental do(s) Trabalhador(es/as) enquanto políticas públicas - "Política de Saúde e Política de Trabalho". Tal analisador vem desorganizar a formato da Organização do Trabalho Psi onde foi produzida a "naturalização" Psicologia Clínica de um lado, Psicologia do Trabalho de outro. Impõe o desafio de articulá-las: seja como uma Clínica do Trabalho, seja para rever práticas clínicas em Saúde Mental do Trabalhador, seja como for... 
Articular Análise Institucional, Saúde Coletiva e Serviço Social passa pela promoção do empowerment (VASCONCELOS, 2003) em estabelecimentos-organizações, o que faculta colocar em pauta questões que remetem à transversalidade (GUATTARI, 1977) entre a assistência à Saúde Mental do Trabalhador e aos entrecruzamentos de saberes e poderes que aí encontramos.

Tecer interconexões com a Assistência a Saúde Mental de Trabalhadores, Análise Institucional, Psicodinâmica do Trabalho e Saúde Coletiva coloca em pauta nossas implicações com a produção do nexo "Análise Institucional e Saúde Coletiva".

O analisador "Lobo Mau" nos conduz a rever a produção-institucionalização do nexo entre Análise Institucional e Saúde Coletiva nos seguintes aspectos:

revelando nossas implicações na construção de tal nexo;

possibilitando nossa inserção em situações de intervenção-formaçãopesquisa;

desvelando o quanto nosso campo de análise exige exploração minuciosa das relações que mantemos com nossas instituições de pertença.

\section{Notas}

${ }^{1}$ A noção de instituição é equívoca (ARDOINO; LOURAU, 2003, p. 25) por podermos abordála tanto como algo que já está aí quanto como em algo em vias de se instituir. É definida como o movimento pelo qual as forças sociais se materializam em formas sociais. A dinâmica e a dialética do instituído (universalidade), do instituinte (particularidade), da institucionalização (singularidade) fazem dela "um objeto flutuante no limite do real, envolto sem cessar nas ondas do imaginário. [Ou seja, a 'instituição' como] um objeto virtual, produzido pela análise, que a elabora ao mesmo tempo em que a interpreta, muito mais do que um objeto real, já aí, sobre o qual se debruçaria a análise para decifrá-lo e traduzi-lo. A instituição é imaterial. Jamais é diretamente apreensível. Só se pode apreendê-la por intermédio da materialidade da organização" (ARDOINO; LOURAU, 2003, p. 17).

2 Foi Castoriadis (1973) quem empregou os termos instituinte e instituído. A formulação castoriadiana da relação Instituído/Instituinte e, portanto, do conceito de Instituição diz que o capitalismo se institui através de um "instituinte originário", isto é, de uma demarcação da organização social em dois campos - "o que vale" (aquilo que de diversas formas produz maisvalia) e "o que não vale" (aquilo que não produz mais-valia).

${ }^{3}$ Baremblitt (1998, p. 187) se aproxima de tal definição quando assinala que o movimento Institucionalista considera o conceito de produção "equivalente ao funcionamento. É aquilo que processa tudo que existe - natural, técnica, subjetiva e socialmente. É a permanente geração de tudo que pode logo tender a cristalizar-se - é o devir, a metamorfose". Produção, por conseguinte, enquanto geração do novo, daquilo que a "Utopia Ativa" persegue: metas e "objetivos" dito "nobres" (NIETZSCHE apud DELEUZE, 1971, 1981) - considerando-os como nunca completamente formulados (sua formulação depende da realidade histórica que a inspira) e como realizável, sempre coletivamente ,- "que orientam os processos Produtivo-DesejanteRevolucionários dos movimentos em seus aspectos instituintes-organizantes" (BAREMBLITT, 1998, p. 196). Frise-se que o processo Produtivo-Desejante-Revolucionário é o próprio fim e meio da Utopia Ativa em cada aqui e agora.

${ }^{4}$ Quanto a nosso duradouro encargo social de "Lobo Mau" em psicologia, assinalamos outras expressões que denunciam o "universo Psi": "empresários morais" (BECKER, 1966), "guardiões da ordem" (COIMBRA, 1995); "moderno poder pastoral" (FOUCAULT, 1983); "fabricantes de interiores" (BAPTISTA, 1987); "psico-tiras" (movimento da contracultura) etc.

5 Além da doença vivenciada pelo trabalhador (primeira penalização), há todo um aparato que justifica a negação do nexo processo saúde-doença e trabalho atribuindo a responsabilidade aos 
trabalhadores/as acidentados/adoecidos (como se estes não fossem suficientemente bons para realizar tal trabalho). Enquanto as intervenções pontuais são realizadas sobre os riscos mais evidentes e os agentes/riscos são assumidos como peculiaridades "naturalizadas" de objetos e meios de trabalho, descontextualizados das razões que se situam em sua origem, reforça-se a utilização de equipamentos de proteção individual (EPI), em detrimento dos que poderiam significar a proteção coletiva; normatizam-se formas de trabalhar consideradas seguras, o que, em determinadas circunstâncias, conforma apenas um quadro de prevenção simbólica. O que caracterizaria a "dupla penalização" (MACHADO; MINAYO-GOMEZ, 1995 apud MINAYO-GOMES \& THEDIMCOSTA, 1997) aí, diz respeito ao não cumprimento de medidas que deveriam assegurar a saúde do trabalhador em seu sentido mais amplo, imputando aos trabalhadores/as os ônus por acidentes e doenças, - concebidos como decorrentes da ignorância e da negligência destes.

${ }^{6}$ Para uma maior contextualização acerca dos debates e discussões quanto aos analisadores, ver Rodrigues, (1992; RODRIGUES; SOUZA, 1991; RODRIGUES; BARROS, 2004; LOURAU, 2004b, BAREMBLITT, 1998; MARTIN, 2004; L'ABBATE, 2004; PEREIRA, 2005).

7 Salientamos que implicação é um conceito oriundo da Análise Institucional (AI) e que se opõe à neutralidade positivista, ao levar em conta que o observador está sempre implicado no campo da observação e sua ação, por mais que aparentemente "inativa", modifica o objeto de estudo, transforma.Vale buscar os instigantes textos de Lourau onde evoca as relações do conceito (LOURAU, 2004b, p. 66-86; 2004d, p. 186-198; 2004e, p. 212-223; 2004f, p. 246-258; 2004g, p. 176-185; 1987-2004h, p. 259-283).

8 Transversalidade é o entrecruzamento de linhas/níveis de determinação do comportamento psicológico e social que são: a linha econômica, a linha política, a linha do desejo (produção desejante) e a linha ideológica. Tal transversalidade, então, é uma "rede de poder" que tende a reproduzir a norma pró-mercado. Ela está em todo lugar e em lugar algum. Ao remeter aos múltiplos vínculos, referências e interferências que nos relacionam ao conjunto do sistema social, o conceito de "transversalidade" (GUATTARI, 1977) - oriundo das pesquisas psicoterápicas e psicanalíticas de Guattari, - atravessa, de um lado, uma espécie de disseminação de um padrão de comportamento social ditado pela sociedade hegemônica; de outro, "um potencial de forças instituintes, as quais, caso venham à tona, poderão produzir o questionamento ou os procedimentos [que são os "focos de resistência" ou as "linhas de fuga"] que conduzam ao processo de mudança em relação ao comportamento hegemônico" (BASTOS, 2001, p.72-73). A transversalidade tanto pode servir para afirmar o poder estabelecido, como também para questioná-lo, repensá-lo.

9 O termo "instituído" engloba não só a ordem estabelecida, os valores, modos de representação e de organização considerados "normais" (a normalidade instituída), como também os procedimentos habituais de previsão (econômica, social e política). Por "instituinte" (LOURAU, 1969-2004a) entenderemos, ao mesmo tempo, a contestação, a capacidade de inovação e, em geral, a prática política como "significante" da prática social. A articulação do conceito de instituição proposta por Lourau apoia-se na lógica dialética de Hegel: o instituinte é o negativo, o que vem negar o instituído (universal). O terceiro momento, o da singularidade hegeliana - através do qual a contradição é superada -, é a institucionalização. Para Hess (HESS; SAVOYE, 2006) o confronto desses dois momentos do conceito é superado nesse terceiro momento, que Lourau denomina institucionalização. Frente as tendências apresentadas pelas instituições e grupos sociais à institucionalização e reprodução do já instituído em paralelo às tendências instituintes, de mudança e renovação, assinalamos o cuidado necessário ao tratar a díade "instituído-instituinte" alertado por Baremblitt (1998, p. 27-38) com relação ao fato de o instituído ser considerado ruim (pela tendência à resistência, à não-mudança, conservadorismo) e o instituinte ser o lado bom (atividade revolucionária, criativa, transformadora) da instituição. A criação de instituições tem por produto, gerar um resultado $\{=$ "instituído"= efeito da atividade instituinte (que seria o processo) $\}$. A chave da "leitura" das questões institucionais só poderá abrir questões a serem analisadas se se abrir à complexidade inerente à instituição onde a dupla dinâmica instituído-instituinte funciona (ou não!) como os dois lados da mesma moeda. "Uma vez que o instituinte careceria completamente de sentido se não se materializasse nos instituídos [enquanto] os instituídos não seriam úteis, funcionais, se não estivessem abertos à potência instituinte" (BAREMBLITT, 1998, p. 32-33).

${ }^{10}$ Neste contexto estaremos considerando "Psicologia Industrial" a fase caracterizada pela preocupação com a produtividade, tendo sido influenciada pelo Taylorismo. $\mathrm{O}$ foco era o indivíduo, que deveria se ajustar à empresa, qualquer que fosse sua forma de gestão. A idéia de bem-estar aí estava associada à lei do menor esforço do trabalhador, já que as operações para a realização de uma tarefa eram encabeçadas pela Organização Científica do Trabalho (OCT). Quando a produtividade 
taylorista começa a esbarrar na insatisfação dos trabalhadores, os fatores psicossociais ligados ao trabalho ganham cena e essa segunda fase, denominada "Psicologia Organizacional", se caracteriza pela tentativa de entender a organização como um grupo. Solapando as máximas tayloristas, o afeto, a "irracionalidade" e principalmente o grupo, mais que o indivíduo começam a surgir como categorias de análise. Surge então a Escola das Relações Humanas (MAYO, 1933) que influencia a Teoria Geral da Administração (TGA). A terceira fase, conhecida por "Psicologia do Trabalho", vem se dedicando a trabalhos ainda pouco absorvidos pelas empresas, embora o movimento dos usuários dos serviços de saúde mental, aliado a sindicalistas e trabalhadores em Saúde Mental venham se fortalecendo na luta pela saúde dos trabalhadores recorrendo ao auxílio da Psicologia do Trabalho (ATHAYDE, 2004). A busca é de melhoria das condições de trabalho (relacionadas também à produção e ao ambiente) e como movimento pela qualidade de vida no trabalho (QVT) visando contribuir para uma ética das relações de trabalho nas organizações. Essa Psicologia está identificada pois, com o estudo da psicodinâmica entre o homem e o trabalho e se caracteriza por vislumbrar nessa relação possibilidades de realização humana, da mesma forma que, para muitos, o trabalho vem sendo um meio de adoecimento. As abordagens do Stress, Psicodinâmica do Trabalho e Análise Institucional, têm sido ferramentas de trabalho na luta pela saúde dos trabalhadores/as. Aos interessados na temática assinalada, sugerimos a discussão de Guirado (1987) a respeito da(s) "Psicologia(s) Institucional(ais)", onde busca situar como se constituem os discursos teóricos sobre e as práticas de intervenção psicológica nas instituições.

${ }^{11}$ Orientada por Sílvia Rodrigues Jardim. Nosso encontro com os participantes dos Seminários do Programa OTSAM-IPUB-UFRJ, possibilitou-nos atravessar a ponte entre Saúde Mental e Trabalho, Saúde do Trabalhador, Saúde Coletiva e Análise Institucional (BISNETO, 1999, 2000, 2001, 2004) participara deste grupo de pesquisas e aí descobrimos todo um trabalho que tem sido desenvolvido na ESS-UFRJ ligando a Análise Institucional e o Serviço Social).

${ }^{12}$ Trabalho orientado por Marisa Palácios (IESC-UFRJ) e Heliana de Barros Conde Rodrigues (UERJ). Consideramos nosso trabalho uma "Avaliação Formativa" sustentada na "Pesquisa-ação" - (Análise Institucional (um mix de "Análise Institucional Sócio-histórica" com "Socioanálise") e Psicodinâmica do Trabalho) (BARBIER, 1985; THIOLLENT, 1997, 1999, 2003; DEJOURS, 1992a, 1992b, 1993a, 1993b; DEJOURS; ABDOUCHELI; JAYET, 1994, 2003; 2004; BOSI; UCHIMURA, 2002, 2004; BOSI; MERCADO-MARTÍNEZ, 2004; DESLANDES; GOMES, 2004; BOSI, 2005; AYRES, 2004; PEDROSA, 2004; RODRIGUES; BARROS, 2003; HESS; SAVOYE, 2006).

${ }^{13}$ De acordo com Ardoino \& Lourau (2003, p. 18) esclarecemos que dizem respeito aos estabelecimentos "os muros, os locais, o mobiliário, tangíveis e visíveis, os agentes com, caso necessário, o uniforme que vestem, atestando o pertencimento do aparelho. São, ainda, as estruturas da organização, a hierarquia, os horários, o emprego do tempo, os regulamentos - já menos evidentes, mais abstratos, porém, apesar de tudo, perceptíveis porque explicitamente significados afixados, codificados (escritos, graduações, estatutos, etc.)". Um conjunto de estabelecimentos integra uma organização que são formas materiais nas quais as instituições se realizam/ "encarnam" (BAREMBLITT,1998, p.184).

${ }^{14}$ Sobre as discussões entre campo de intervenção e campo de análise, ver Rodrigues \& Souza, 1991; Baremblitt, 1998; Rodrigues, 1999a ,1999b, 2004; Martin, 2004.Chamaremos de campo de intervenção o território existencial definido pela encomenda (sendo que esta tem origem em demandas. Como é feito o pedido de ação mais ou menos oficialmente e que é inseparável da produção histórica da legitimação para exercer determinada função na divisão sócio-técnica do trabalho?) Já o campo de análise é o sistema de referência teórico na medida em que este se torna operatório em uma situação de pesquisa-ação: equivale ao "institucional ou sócio-histórico, abrindo virtualidades à desnaturalização, inclusive, da instituição da clientela" (RODRIGUES, 1999a). É o campo de análise que fornece chaves de 'leitura' do campo de intervenção (como este funciona? Como articulam-se suas determinações? De que forma são gerados seus efeitos? Tomaremos o conceito de Efeitos como equivalente a Funções sendo que quanto maior a preservação de tal nexo menor o risco de que um pensamento ou prática se torne mera técnica a consumir no mercado capitalístico) (RODRIGUES, 2004).

15 "O conceito de ruído é baseado no preconizado por Flores (1989) de que a quebra do silêncio do cotidiano pode e deve ser percebida como a presença de processos instituintes que não foram contemplados pelo modelo de organização e gestão do equipamento institucional em foco e que abrem possibilidades de interrogações sobre o modo instituído como se opera o trabalho e o sentido de suas ações naquele equipamento" (JORGE, 2002, p. 96-97). Lembramos que equipamento, 
enquanto conceito adotado pelo Movimento Institucionalista, refere-se a conglomerados complexos, montagens de variadas materialidades. Traduzidas em recursos técnicos, podem instrumentalizar-se via comunicação de massas (grande porte) ou num nível mais modesto como em arquivos, impressoras, relógios de ponto etc (BAREMBLITT; MELO, 1998, p. 170).

${ }^{16}$ Embora sem fazer referência explícita à definição de analisador da versão pavloviana, é nesta fonte que Torrubia e Guattari se abastecem ao retomar o conceito nos trabalhos de Psicoterapia Institucional (LOURAU, 2004b, p.70). Caso se queira percorrer o uso do conceito de analisador por estudiosos de diferentes campos e de variadas tendências, podemos acompanhar a empreitada de Lapassade (1971) e Lourau (1973), ao investigarem a gênese do conceito na biologia, física, psicologia e psicanálise.

${ }^{17} \mathrm{Na}$ realidade, estamos falando de uma instância de enunciação a qual, ao mesmo tempo que institui um sujeito, o assujeita a determinadas regras de um contexto. Cabe aqui o lembrete 'a la' Lourau de que, embora definir e elucidar analisadores seja uma das regras da socioanálise (Análise Institucional em situação de intervenção), seria incabível eximirmo-nos disso: "os analisadores (...) não deveriam ser abusivamente confundidos com as intuições individuais de uma ou outra pessoa implicada na situação, mesmo que tal pessoa seja um socioanalista" (LOURAU, 1977, 2004, p. 132). No mais, "o objetivo da Análise Institucional em situação de intervenção (Socioanálise) é validar o conceito de analisador" (LOURAU, 1977 e 2004b, p. 78, grifo nosso).

${ }^{18}$ Lembramos que tal publicação é contemporânea da suntuosa produção da Análise Institucional no Brasil.

${ }^{19}$ Há quem considere a Saúde do Trabalhador um sub-ramo da Saúde Coletiva (MINAYO-GOMES; THEDIM-COSTA, 1997; LACAZ, 1996, 1997, 2000; MINAYO-GOMES; LACAZ, 2005; DIAS; HOEFEL, 2005; BRITO, 2004) e a Saúde Mental e Trabalho como filha especial/predileta da Saúde do Trabalhador (JARDIM; SILVA-FILHO, 2001, p.197) ou "uma subárea do campo da Saúde do Trabalhador" (SATO, 1996, 2002; SATO; BERNARDO, 2005). Enfatizamos que a saúde é dos trabalhadores (que um dos ditos campos singulariza) e não de uns ou de outros que pretendem capturá-la nas amarras das instituições (pelas quais são igualmente capturados). Considerando o cenário, percurso, discursos, dilemas e desafios que permeiam e conformam a construção do campo da Saúde do Trabalhador, podemos dizer que tal construção é tecida no bojo das contribuições da Medicina Social Latino-Americana e da Saúde Coletiva, no âmbito das elaborações do campo teórico-abstrato Saúde e Trabalho. Esta é a hipótese sustentada por Lacaz (1996), que, nas investigações dedicadas ao campo da Saúde do Trabalhador, apresentao como uma formação discursiva da Academia, dos Serviços e do Movimento Sindical. O discurso aí engendrado diz respeito a conceitos, enunciados, normas e práticas para fazer frente ao da Medicina do Trabalho-Saúde Ocupacional.Dentre algumas fontes inspiradoras da luta pela saúde que norteiam o campo da Saúde do Trabalhador, destacamos o "Modelo Operário Italiano", a Reforma Sanitária (nela situando o movimento Psico-higienista e a forte inspiração na experiência da Reforma Sanitária Italiana), a Reforma Psiquiátrica (luta antimaniconial de inspiração basagliana), o Discurso Preventivista e o Modelo da Promoção em Saúde.

${ }^{20}$ Há uma série de discussões em torno do "modo de produção" dos analisadores. Quando dizemos que o analisador dirige a análise - daí o analisador substituir o analista -, "queremos indicar, como regra fundamental, que o analista não deve procurar subtrair-se aos efeitos analisadores do dispositivo de intervenção" (LOURAU, 2004b, p. 84). "O intelectual não é o analisador e sim o analista, com possibilidade de tomar consciência dos efeitos dos analisadores que desencadeiam sua intervenção" (LOURAU, 2004b, p. 80). Além de reconhecer e legitimar a existência dos analisadores, "deve compreender que somente os analisadores o constituem como analista" (LOURAU, 2004b, p. 80). A inversão epistemológica que coloca "o primado do analisador sobre o analista" (LAPASSADE, 1973) constitui o novo espírito científico (GUATTARI, 1973) no qual "é o analisador que realiza a análise" (LAPASSADE, 1973), onde "a análise é também analisador" (LOURAU, 1973). A virada epistemológica aí produzida através do conceito de analisador e sua aplicação condiz com a união entre "a análise e o fenômeno que a engendra, provocando assim uma inversão da relação entre o objeto real e o objeto de conhecimento, na medida em que eles não são mais considerados como entidades separadas" (L'ABBATE, 2004, p. 82).

${ }^{21}$ Dejours (1992a) recorre ao conceito de "situações de trabalho", desenvolvido por Guérin et al. (1991), para definí-las como um conjunto complexo que inclui a dimensão técnica, as condições, a organização e as relações de trabalho. 
${ }^{22}$ O gestor-corretor que em 1996 encomendara "o trabalho com os corretores" (vide capítulo "Que Intervenções?" em Merhy-Silva, 2006).

${ }^{23}$ Como o leitor poderá notar, esta fala-chave, é chave de leitura para abrir/desvelar, revelar o analisador "Lobo Mau"; e sua descrição-contextualização pode ser melhor apreciada no desenrolar do analisador "Cooperações?" descrito por Merhy-Silva (2006).

${ }^{24}$ Hesitamos quanto ao argumento-prescrição ser contrário ao que pretendia ser (um movimento instituinte). A conotação de defesa de um território parecia fundamental nas batalhas de exercício de poder que ali se desenvolviam: relação capital-trabalho, hierarquia-trabalhadores, processo saúde-doença. É nesta arena que lutamos pela construção de "espaços de discussão" (DEJOURS; ABDOUCHELI; JAYET, 2004) no trabalho dos Corretores/as, colocando em pauta a relação que têm com o próprio trabalho e a distância entre "trabalho real" e "trabalho prescrito" na Corretagem de Imóveis. Ao questionarmos o hiato entre a organização do trabalho prescrita e a organização do trabalho real, tivemos que nos situar frente aos discursos organizacionais que buscam se apropriar da Saúde Mental. Articulamos os conceitos de "Trabalho Prescrito" e "Trabalho Real" - oriundos da Ergonomia (WISNER, 1981, 1994; DANIELLOU, 1992; VIDAL, 1997, MONTMOULLIN,1993; PALÁCIOS, 1999). A forma como o trabalho deve ser executado do ponto de vista do pessoal de concepção (formas de utilizar as máquinas e demais instrumentos de trabalho, o tempo alocado a cada operação, as normas operatórias) é o que define o trabalho prescrito. Já o trabalho real, sempre diferente do prescrito, é aquele que é efetivamente realizado. Tanto na linha de montagem em setores clássicos da produção quanto em sistemas automatizados, a distância entre trabalho prescrito e real atinge as pessoas, as empresas e a coletividade como um todo.

\section{REFERÊNCIAS}

ALBUQUERQUE, J. A. G. Metáforas da Desordem. Rio de Janeiro: Paz e Terra, 1978.

Instituição e Poder. Rio de Janeiro: Graal, 1982.

ALTOÉ, S. Psicoterapia Institucional e Análise Institucional. In ALTOÉ, S.; RODRIGUES, H. B. C. (Org.). SaúdeLoucura 8: Análise Institucional. São Paulo: Hucitec, 2004. p. 39-64.

ARDOINO, J.; LOURAU, R. (Org.). As Pedagogias Institucionais. Tradução de João Batista Martins e Heliana de Barros Conde Rodrigues. São Carlos: Rima, 2003.

ATHAYDE, M. R. C. Produção da análise, análise da produção. In: RODRIGUES, H. B. C.; LEITÃO, M. B. S.; BARROS, R. D. B. (Org.). Grupos e Instituições em Análise. Rio de Janeiro: Rosa dos Tempos, 1992. p. 157-171.

Psicologia e Trabalho: que relações? In: JACÓ-VILELA, A. M.; MANCEBO, D. (Org.). Psicologia Social: abordagens sócio-históricas e desafios contemporâneos. 2. ed. Rio de Janeiro: EdUERJ, 2004. p. 197-221.

AYME, J. La psychothérapie institutionnelle: origine, histoire, tendances. In: MARIN, P. (Org.). Pratiques institutionnelles et théorie des psychoses: actualité de la psychothérapie institutionnelle. Paris: LHAarmattan, 1995. In: ALTOÉ, S.; RODRIGUES, H. B. C. (Org.). SaúdeLoucura 8: Análise Institucional. São Paulo: Hucitec, 2004. p. 39-64. 
Fabiana Nunes Merhy-Silva

AYRES, J. R. Norma e formação: horizontes filosóficos para as práticas de avaliação no contexto da promoção da saúde. Ciência \& Saúde Coletiva, [S.1.], v. 9, n. 3, p. 583-592, jul./set. 2004. Disponível em: <www.scielo.br/csc $>$. Acesso em: 12 ago. 2005.

AZEVEDO, M. A. A formação do Psicólogo organizacional e alguns dilemas da psicologia como ciência. Cadernos de Psicologia - PUC-MG, Belo Horizonte, v. 1, n. 2, p. 35-44, dez. 1993.

BAPTISTA, L. A. S. Algumas Histórias sobre a Fábrica de Interiores. 1987. Tese (Doutorado em Psicologia)-Instituto de Psicologia, Universidade de São Paulo, São Paulo, 1987.

BARBIER, R. A pesquisa-ação na instituição educativa. Rio de Janeiro: J. Zahar, 1985.

BAREMBLITT, G. Compêndio de Análise Institucional e outras correntes: teoria e prática. Rio de Janeiro: Record-Rosa dos Tempos, 1998.

BAREMBLITT, G.; MELO, C. R. de. Glossário. In: BAREMBLITT, G. Compêndio de Análise Institucional e outras Correntes: Teoria e prática. Rio de Janeiro: Record; Rosa dos Tempos, 1998. p. 149-197.

BARROS, R. D. B.; BRASIL, V. V. Cartografia de um trabalho socioanalítico. In: RODRIGUES, H. B. C.; LEITÃO, M. B. S.; BARROS, R. D. B. (Org.). Grupos e Instituições em Análise. Rio de Janeiro: Rosa dos Tempos, 1992. p. 228-248.

BASTOS, R. L. Obra de Arte e Vida: Psicologias Sociais, diferentes subjetividades na estética da existência. Londrina: Universidade Estadual de Londrina, 2001.

. Psicanálise/institucional, ordem dos discursos e artepensamento. In: . Poética e psicanálise: artepensamento entre campo ficcional e campo psicanalítico, diferentes subjetividades. Rio de Janeiro: E-papers, 2004. p. 158176.

BECKER, H. Outsiders: studies in sociology of deviance. New York: The Free Press, 1966.

BISNETO, J. A. Análise Institucional, Serviço Social e Subjetividade: uma introdução. Revista Transversões - ESS-UFRJ, Rio de Janeiro, v. 1, n. 1, p. 132$168,1999$.

. A Análise Institucional no processo de renovação do Serviço Social no Brasil. In: VASCONCELOS, E. M. Saúde Mental e Serviço Social. São Paulo: Cortez, 2000. p. 291-328. 
"Lobo mau": analisador da transversalidade entre organização do trabalho \& saúde mental?

BISNETO, J. A. Análise Institucional do Serviço Social em Saúde Mental. 2001. Tese (Doutorado)-Escola de Serviço Social, Universidade Federal do Rio de Janeiro, Rio de Janeiro, 2001.

A Socioanálise no Serviço Social no Brasil. In: ALTOÉ, S.; RODRIGUES, H. B. C. (Org.). SaúdeLoucura 8: Análise Institucional. São Paulo: Hucitec, 2004. p. 29-38.

BOSI, M. L. M. Comunicação Pessoal. Rio de Janeiro: Rede Interna NESCUFRJ, 2005.

BOSI, M. L. M.; UCHIMURA, K. Y. Qualidade e subjetividade na avaliação de programas e serviços em saúde. Cadernos de Saúde Pública, Rio de Janeiro, v. 18, n. 6, p. 1561-1569, nov./dez. 2002.

A Polissemia da Qualidade na Avaliação de Programas e Serviços de Saúde. In: BOSI, M. L. M.; MERCADO-MARTÍNEZ, F. (Org.). Pesquisa Qualitativa de Serviços de Saúde. Petrópolis: Vozes, 2004. p. 75-98.

BOSI, M. L. M.; MERCADO-MARTÍNEZ,F. (Org.). Pesquisa Qualitativa de Serviços de Saúde. Petrópolis: Vozes, 2004.

BRITO, J. Saúde do trabalhador: reflexões a partir da abordagem ergológica. In: ALVAREZ, D.; ATHAYDE, M.; BRITO, J.; FIGUEIREDO, M. (Org.). Labirintos do trabalho: interrogações e olhares sobre o trabalho vivo. Rio de Janeiro: DP\&A, 2004. p. 91-114.

CAMPOS, G. W. de S. Saúde Pública e Saúde Coletiva: campo e núcleo de saberes e práticas. Revista Ciência \& Saúde Coletiva, Rio de Janeiro, v. 5, n. 2, p. 219-230, 2000.

CASTORIADIS, C. L'institution imaginaire de la societé. Paris: Seuil, 1973.

CODO, W.; LANE, S. T. (Org.). Psicologia Social: o homem em movimento. São Paulo: Brasiliense, 1994.

CODO, W. O Papel do Psicólogo na Organização Industrial (Notas sobre o "Lobo Mau" em Psicologia). In: CODO, W.; LANE, S. T. (Org.). Psicologia Social: o homem em movimento. São Paulo: Brasiliense, 1994. p. 193-202.

CODO, W. et al. O Trabalho Enlouquece? Um encontro entre a clínica e o trabalho. Petrópolis: Vozes, 2004.

COIMBRA, C. M. B. Guardiães da ordem: uma viagem pelas práticas psi no Brasil do "Milagre". Rio de Janeiro: Oficina do Autor, 1995. 
Fabiana Nunes Merhy-Silva

DANIELLOU, F. Le Statut de la Pratique et des Connaissances dans l'Intervention Ergonomique de Conception. Paris: Université de Toulouse, 1992. Document de synthèse présenté en vue d'obtenir l'Habilitation à diriger des recherches.

DEJOURS, C. Por um novo conceito de saúde. Revista Brasileira de Saúde Ocupacional, São Paulo, v. 14, n. 54, p. 7-11, abr./maio/jun. 1986.

. A loucura do trabalho: estudo de psicopatologia do trabalho. São Paulo: Cortez-Oboré, 1992a.

. Uma nova visão do sofrimento humano nas organizações. In: CHANLAT, D. F. (Org). O indivíduo na Organização: dimensões esquecidas. São Paulo: Atlas, 1992b, v. I. p. 149-173.

Addendum théorique. In: Travail Usure Mentale: Essai de

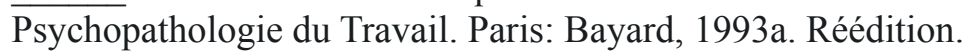

. Coopération et construction de l'identité en situation de travail. $L a$ marche du temps: futur antérieur, Paris, n.16, p. 41-52, 1993b.

DEJOURS, C; ABDOUCHELI, E; JAYET, C. Psicodinâmica do Trabalho: contribuições da escola dejouriana à análise da relação prazer, sofrimento e trabalho. São Paulo: Atlas, 1994. 2003.

. A banalização da injustiça social. 5. ed. rev. ampl. Rio de Janeiro: FGV,

. Christophe Dejours: da psicopatologia à psicodinâmica do trabalho. Tradução de Franck Soudant. LANCMAN, S.; SZNELWAR, L. I. (Org.). Rio de Janeiro: Fiocruz; Brasília: Paralelo 15, 2004.

DELEUZE, G. Nietzsche y la Filosofia. Barcelona: Anagrama, 1971.

. Nietzsche. Lisboa: Edições 70, 1981.

DESLANDES, S. F.; GOMES, R. A pesquisa qualitativa nos serviços de saúde. In: BOSI, M. L. M.; MERCADO-MARTÍNEZ, F. (Org.). Pesquisa Qualitativa de Serviços de Saúde. Petrópolis: Vozes, 2004. p. 99-120.

DIAS, E. C.; HOEFEL, M. G. O desafio de implementar as ações de saúde do trabalhador no SUS: a estratégia da RENAST. Ciência \& Saúde Coletiva, Rio de Janeiro, v. 10, n. 4, out./dez., 2005.

FOUCAULT, M. Microfísica do Poder. Rio de Janeiro: J. Zahar, 1979. 
"Lobo mau": analisador da transversalidade entre organização do trabalho \& saúde mental?

FOUCAULT, M. El Ordem del Discurso. Barcelona: Tusquets, 1980.

The subject and power. In: DREYFUS, H. L.: RABINOW, P. (Ed.). Michel Foucault: beyond structuralism and hermeneutics. $2^{\text {nd }}$ ed. Chicago: University of Chicago Press, 1983. p. 208-228.

A Ordem dos Discursos. São Paulo: Loyola, 1996.

História da Sexualidade 1: a vontade de saber. 11. ed. Rio de Janeiro: Graal, 1988.

GUATTARI, F. Um Novo Espírito Científico. In: Liminaire de Recherches, março, 1973. In: ALTOÉ, S. (Org.). René Lourau: analista institucional em tempo integral. São Paulo: Hucitec, 2004. p. 66-86.

A Transversalidade. In: GUATTARI, F.; ROLNIK, S. Revolução Molecular: pulsações políticas do desejo. São Paulo: Brasiliense, 1977.

GUATTARI, F.; ROLNIK, S. Revolução Molecular: pulsações políticas do desejo. São Paulo: Brasiliense, 1977. Vozes, 2005.

Micropolítica: cartografias do desejo. 7. ed. rev. e ampl. Petrópolis:

GUÉRIN, F. et al. Comprendre le travail pour le transformer: la pratique de L'ergonomie. Paris: Anact, 1991.

GUIRADO, M. Psicologia Institucional. São Paulo: EPU, 1987.

Instituição e relações afetivas: o vínculo com o abandono. 2. ed. rev. e ampl. São Paulo: Casa do Psicólogo, 2004.

HESS, R. La Socianalyse. Paris: Éditions Universitaires, 1975.

HESS, R.; AUTHIER M. L'analyse institutionnelle (1981). Paris: PUF, 1994.

HESS, R.; SAVOYE, A. A Análise Institucional. Tradução de João Batista Martins e Heliana de Barros Conde Rodrigues. São Carlos: Rima, 2006. No prelo.

JACQUES, M. da G.; CODO, W. (Org.). Saúde Mental \& Trabalho: leituras. Petrópolis: Vozes, 2002.

JARDIM, S. R.; SILVA FILHO, J. F. (Org.). A Danação do Trabalho: organização do trabalho e sofrimento psíquico. Rio de Janeiro: Te Corá Editora, 1997. 
JARDIM, S. R.; SILVA FILHO, J. F. O Desemprego do trabalho na saúde mental: campo e poder do diagnóstico psiquiátrico na assistência dos trabalhadores. In: VENÂNCIO, A. T.; CAVALCANTI, M. T. (Org.). Saúde Mental: campo, poderes e discursos. Cadernos IPUB-UFRJ, Rio de Janeiro, p. 193-213, 2001.

JORGE, A. O. A. Gestão hospitalar sob a perspectiva da micropolitica do trabalho vivo. 2002. Tese (Doutorado)-FCM/UNICAMP, Campinas, 2002.

L'ABBATE, S. Uma reflexão sobre o analisador dinheiro num trabalho de longa duração. In: ALTOÉ, S.; RODRIGUES, H. B. C. (Org.). SaúdeLoucura 8: Análise Institucional. SãoPaulo: Hucitec, 2004. p. 79-100.

LACAZ, F. A. C. Saúde do Trabalhador: um estudo sobre as formações discursivas da Academia, dos Serviços e do Movimento Sindical. 1996. Tese (Doutorado)Unicamp, São Paulo, 1996.

. Saúde dos trabalhadores: cenário e desafios. Cadernos de Saúde Pública, Rio de Janeiro, v. 13, n. 2, p. 7-19, 1997.

. Sobre a necessidade de revisão do modelo de atenção à saúde dos trabalhadores no Sistema Único de Saúde. Ciência \& Saúde Coletiva, Rio de Janeiro, v. 5, n. supl., p. 489-490, 2000.

LAPASSADE, G. L'arpenteur. Paris: ÉPI, 1971.

. Analyse Institutionnelle et Socianalyse. Connexions, Paris: EPI, 1973.

. El analizador y el analista. Barcelona: Gedisa, 1979.

LOURAU, R. Pour une théorie des analyseurs (fragments). Connexions 6. Paris: EPI, 1973.

. L'instituant contre l'institué. Paris: Anthropos, 1969. O instituinte contra o instituído. Tradução de Paulo Schneider. In: ALTOÉ, S.(Org.). René Lourau: analista institucional em tempo integral. São Paulo: Hucitec, 2004a. p. 47-65.

. Objeto e método da Análise Institucional. In: El Análisis Institucional. Madri: Campo Aberto, 1977. Tradução de Heliana de Barros Conde Rodrigues e Patrícia Jacques Fernandes. In: ALTOÉ, S. (Org.). René Lourau: analista institucional em tempo integral. São Paulo: Hucitec, 2004b. p. 66-86.

. Le champ socianalytique. In: Interventions socianalytiques. Paris: Antropos, 1996. Tradução de Paulo Schneider. O Campo Socianalítico. In: ALTOÉ, S. (Org.). René Lourau: analista institucional em tempo integral. São Paulo: Hucitec, 2004c. p.224-245. 
"Lobo mau": analisador da transversalidade entre organização do trabalho \& saúde mental?

LOURAU, R. Implicação e sobreimplicação. In: ALTOÉ, S. (Org.). René Lourau: analista institucional em tempo integral. São Paulo: Hucitec, 2004d. p. 186-198.

Implicação-transdução. In: ALTOÉ, S. (Org.). René Lourau: analista institucional em tempo integral. São Paulo: Hucitec, 2004e. p. 212-223.

Implicação: um novo paradigma? In: ALTOÉ, S. (Org.). René Lourau: analista institucional em tempo integral. São Paulo: Hucitec, 2004f. p. 246-258.

Grupos e Instituição. In: ALTOÉ, S. (Org.). René Lourau: analista institucional em tempo integral. São Paulo: Hucitec, 2004g. p. 176-185.

Uma técnica de análise de implicações: B. Malinowski, diário de etnógrafo (1987). In: ALTOÉ, S. (Org.). René Lourau: analista institucional em tempo integral. São Paulo: Hucitec, 2004h. p. 259-283.

MARAZINA, I. Trabalhador de Saúde Mental: encruzilhada da Loucura. In: LANCETTI, A. (Org.). SaúdeLoucura 1. São Paulo: Hucitec, 1989. p. 69-74.

MARTIN, A. René, os analisadores históricos, as loucas da Praça de Maio. In: ALTOÉ, S.; RODRIGUES, H. B. C. (Org.). SaúdeLoucura 8: Análise Institucional. São Paulo: Hucitec, 2004. p. 165-189.

MAYO, E. Human Problems of An Industrial Civilization. Nova York: Macmillan Company, 1933.

MERHY, E. E.; ONOCKO, R. (Org.). Agir em saúde: um desafio para o público. 2 ed. São Paulo: Hucitec, 1997. Saúde em debate; 108. Série Didática; 6.

em Dabate; 145

Saúde: a cartografia do trabalho vivo. São Paulo: Hucitec, 2002. Saúde

MERHY-SILVA, F. N. Análise Institucional, Psicodinâmica do Trabalho \& Saúde Coletiva: tecendo interconexões com a assistência à saúde mental de trabalhadores corretores de imóveis (1996-2006). 2006. Dissertação (Mestrado)-NESC/IESCUniversidade Federal do Rio de Janeiro, Rio de Janeiro, 2006.

MINAYO, M. C. de S. Um desafio sociológico para a educação médica. Revista Brasileira de Educação Médica - ABEM, Rio de Janeiro, v. 15, n. 1, p. 25-32, 1991.

MINAYO-GOMEZ, C.; THEDIM-COSTA, S. M. F. A Construção do Campo da Saúde do Trabalhador: percurso e dilemas. Rio de Janeiro, Cadernos de Saúde Pública, v. 13, n. 2, p. 21-32, 1997. 
MINAYO-GOMEZ, C.; LACAZ, F. A. C. Saúde do Trabalhador: novas-velhas questões. Ciência \& Saúde Coletiva, Rio de Janeiro, v. 10, n. 4, p. 797-807, out./ dez. 2005.

MONTMOULLIN, M. L'Ergonomie. Paris: La Découverte, 1993. Collection Repères, mimeografado.

OURY, J. Psychiatrie et psychothérapie institutionnelle: traces et configurations précaires. Paris: Payot, 1976.

PALÁCIOS, M. Sofrimento psíquico e trabalho: um estudo de caso sobre o sofrimento psíquico dos trabalhadores e suas relações com o trabalho de caixa em uma grande empresa estatal bancária. 1999. Tese (Doutorado)-COPPE-UFRJ, Universidade Federal do Rio de Janeiro, Rio de Janeiro, 1999.

PEDROSA, J. I. S. Perspectivas na avaliação em promoção da saúde: uma abordagem institucional. Ciência \& Saúde Coletiva. [online]. v. 9, n. 3, p. 617626, jul./set. 2004. Disponível em: <www.scielo.br/csc $>$. Acesso em: 6 fev. 2005.

PEREIRA, W. C. C. et al. Movimento institucionalista. In: PEREIRA, W. C. C. (Org.). Análise Institucional na vida religiosa consagrada. Belo Horizonte: Publicações CRB, 2005. p. 59-90.

RODRIGUES, H. B. C.; SOUZA, V. L. B de. A Análise Institucional e a Profissionalização do Psicólogo. In: SAIDON, O.; KAMHAGI, V. R. (Org.). Análise Institucional no Brasil. Rio de Janeiro: Rosa dos Tempos, 1991. p. 27-45.

RODRIGUES, H. B. C. Psicanálise e Análise Institucional. In: RODRIGUES, H. B. C.; LEITÃO, M. B. S.; BARROS, R. D. B. (Org.). Grupos e Instituições em Análise. Rio de Janeiro: Rosa dos Tempos, 1992, p. 42-55. Coleção Análise Institucional.

. Compreensão e crítica da Psicologia do Trabalho: relatos e recortes sobre formação em saúde mental do trabalhador. In: SILVA FILHO, J. F.; JARDIM, S. (Org.). A Danação do Trabalho: organização do trabalho e sofrimento psíquico. Rio de Janeiro: Te Corá IPUB, 1997. p. 335-342.

. Notas sobre o paradigma institucionalista: preâmbulo político-conceitual às aventuras históricas de 'sócios'e 'esquizos' no Rio de Janeiro. Transversões ESS-UFRJ, Rio de Janeiro, v.1 ,n. 1, p. 169-199, 1999a.

. Sobre as histórias das práticas grupais: considerações sobre um intrincado problema. In: JACÓ-VILELA, A. M.; MANCEBO, D. (Org.). Psicologia Social: abordagens sócio-históricas e desafios contemporâneos. Rio de Janeiro: EdUERJ, 1999b, p.111-165. 
"Lobo mau": analisador da transversalidade entre organização do trabalho \& saúde mental?

RODRIGUES, H. B. C.; BARROS, R. D. B. Socioanálise e práticas grupais no Brasil: um casamento de heterogêneos. Revista Psicologia Clínica - PUC, Rio de Janeiro, v. 15, n. 1, p. 61-74, 2003.

Análise Institucional francesa e transformação social: o tempo (e contratempo) das intervenções. In: ALTOÉ, S.; RODRIGUES, H. B. C. (Org.). SaúdeLoucura 8:Análise Institucional. São Paulo: Hucitec, 2004. p. 115-164.

SARTRE, J-P. Crítica de la razón dialéctica. Buenos Aires: Losada, 1963.

SATO, L. As implicações do conhecimento prático para a vigilância em saúde do trabalhador. Cadernos de Saúde Pública, Rio de Janeiro, v. 12, n. 4, p. 489-495, out./dez. 1996.

prevenção de agravos à saúde do trabalhador: replanejando o trabalho através das negociações cotidianas. Cadernos de Saúde Pública, Rio de Janeiro, v. 18 , n. 5 , p. $1147-1157,2002$.

SATO, L.; BERNARDO, M. H. Saúde mental e trabalho: os problemas que persistem. Ciência \& Saúde Coletiva, Rio de Janeiro, v. 10, n. 4, out./dez., 2005.

THIOLlENT, M. Pesquisa-Ação nas Organizações. São Paulo: Atlas, 1997.

Notas para o debate sobre pesquisa-ação. In: BRANDÃO, C. R. (Org.). Repensando a Pesquisa Participante. São Paulo: Brasiliense, 1999, p. 82-103.

Metodologia da Pesquisa-Ação. 12 ed. São Paulo: Cortez, 2003.

VASCONCELOS, E. M. Desinstitucionalização e interdisciplinaridade em Saúde Mental. In: VASCONCELOS, E. M.; FURTADO, T. (Ed.). Cadernos IPUB, n. 7: Saúde Mental e Desinstitucionalização: reinventando serviços. Rio de Janeiro, Instituto de Psiquiatria da UFRJ, 1997. p. 19-42.

Mundos Paralelos, até quando? Os psicólogos e o campo da saúde mental pública no Brasil nas duas últimas décadas. In: JACÓ-VILELA, A. M. ; JABUR, F.; RODRIGUES, H. B. (Org.). Clio-Psiquê: Histórias da Psicologia no Brasil. Rio de Janeiro: UERJ/NAPE, 1999.

Reinvenção da cidadania no campo da saúde mental e estratégia política no movimento dos usuários. In: VASCONCELOS, E. M. (Org.). Saúde Mental e Serviço Social. São Paulo: Cortez, 2000. p. 69-95.

O poder que brota da dor e da opressão: empowerment, sua história, teorias e estratégias. São Paulo: Paulus, 2003.

. et al. (Org.). Cadernos de Textos - III CONFERÊNCIA NACIONAL DE $\overline{S A U ́ D E}$ MENTAL. Brasília: Ministério da Saúde, 2001. 
Fabiana Nunes Merhy-Silva

VENÂNCIO, A. T.; CAVALCANTI, M. T. (Orgs). Saúde Mental: campo, poderes e discursos. Rio de Janeiro: CUCA-IPUB/UFRJ, 2001.

VIDAL, M. C. A materialidade da Organização do Trabalho como objeto da Intervenção Ergonômica. In: SILVA FILHO, J. F.; JARDIM, S. (Org.). A Danação do Trabalho: Organização do Trabalho e Sofrimento Psíquico. Rio de Janeiro: Te Corá, 1997. p. 89-138.

WISNER, A. Vers une Antropotechnologie. Paris: CNAM, 1981.

. A Inteligência no Trabalho: textos selecionados de ergonomia. São Paulo: Fundacentro, 1994.

Recebido em: novembro de 2005

Aceito em: maio de 2007 